This is a post-peer-review, pre-copyedit version of an article published in Mar Biotechnology. The final authenticated version is available online at:

https://doi.org/10.1007/s10126-019-09886-x

\title{
1 Characterization of the European sea bass (Dicentrarchus 2 labrax) gonadal transcriptome during sexual development
}

Ribas L ${ }^{1+}$, Crespo B ${ }^{2,3+}$, Sánchez-Baizán $\mathrm{N}^{1}$, Xavier $\mathrm{D}^{4}$, Kuhl $\mathrm{H}^{5,6}$, Rodriguez JM ${ }^{7,8}$, Díaz $\mathrm{N}^{1,9}$, Boltañá $\mathrm{S}^{10,11}$, MacKenzie $\mathrm{S}^{10,12}$, Moran $\mathrm{F}^{4}$, Zanuy $\mathrm{S}^{2}$, Gómez $\mathrm{A}^{2^{*}}$, Piferrer $\mathrm{F}^{1 *}$

7

${ }^{1}$ Institute of Marine Sciences (ICM), Spanish National Research Council (CSIC), Barcelona, Spain

${ }^{2}$ Institute of Aquaculture of Torre de la Sal (IATS-CSIC), Castellón, Spain

${ }^{3}$ Current address: UCL GOS Institute of Child Health, University College London, London, UK

${ }^{4}$ Dept. of Biochemistry and Molecular Biology I, Complutense University, Madrid, Spain

${ }^{5}$ Max Planck Institute for Molecular Genetics, Berlin, Germany

${ }^{6}$ Current address: Department of Ecophysiology and Aquaculture, Leibniz Institute for Freshwater Ecology and Inland Fisheries, Berlin, Germany.

${ }^{7}$ Spanish National Bioinformatics Institute, Madrid, Spain

${ }^{8}$ Current address: Cardiovascular Proteomics Laboratory, Centro Nacional de Investigaciones Cardiovasculares Carlos III (CNIC), Madrid, Spain

${ }^{9}$ Current address: Max Planck Institute for Molecular Biomedicine, Muenster, Germany

${ }^{10}$ Autonomous University of Barcelona, Barcelona, Spain.

${ }^{11}$ Current address: Interdisciplinary Center for Aquaculture Research (INCAR), Dept. of Oceanography, Biotechnology Center, University of Concepción, Concepción, Chile ${ }^{12}$ Current address: Institute of Aquaculture, University of Stirling, Scotland, UK

${ }^{+}$These authors contributed equally

*Correspondence: Dr. Francesc Piferrer, Institute of Marine Sciences, Spanish Council for Scientific Research (CSIC), Barcelona, Spain. Tel. +34-932309567; fax, +34932309555; e-mail: piferrer@icm.csic.es. Dr. Ana Gómez. Institute of Aquaculture Torre la Sal (CSIC). Ribera de Cabanes s/n. 12595 Torre la Sal. Castellón. Spain. Tel. +34 964 319500; fax, +34 964 319509; e-mail: a.gomez@csic.es 


\section{Abstract}

45 The European sea bass is one of the most important cultured fish in Europe and has a marked sexual growth dimorphism in favor of females. It is a gonochoristic species with polygenic sex determination, where a combination between still undifferentiated genetic factors and environmental temperature determine sex ratios. The molecular mechanisms responsible for gonadal sex differentiation are still unknown. Here, we sampled fish

50 during the gonadal developmental period (110 to 350 days post fertilization, dpf), and performed a comprehensive transcriptomic study by using a species-specific microarray.

52 This analysis uncovered sex-specific gonadal transcriptomic profiles at each stage of

53 development, identifying larger number of differentially expressed genes in ovaries

54 when compared to testis. The expression patterns of 54 reproduction-related genes were 55 analyzed. We found that $h s d 17 \beta 10$ is a reliable marker of early ovarian differentiation.

56 Further, three genes, $p d g f b, \operatorname{sn} x l$ and $n f y$, not previously related to fish sex

57 differentiation, were tightly associated with testis development in the sea bass.

58 Regarding signaling pathways, lysine degradation, bladder cancer and NOD-like

59 receptor signaling were enriched for ovarian development while eight pathways

60 including basal transcription factors and steroid biosynthesis were enriched for testis

61 development. Analysis of the transcription factor abundance showed an earlier increase

62 in females than in males. Our results show that, although many players in the sex

63 differentiation pathways are conserved among species, there are peculiarities in gene 64 expression worth exploring. The genes identified in this study illustrate the diversity of 65 players involved in fish sex differentiation and can become potential biomarkers for the 66 management of sex ratios in the European sea bass and perhaps other cultured species.

67

68

69

70

71 Keywords: genomics, transcriptomics, reproduction, sex differentiation, gonads, 72 aquaculture 


\section{Introduction}

Many fish species exhibit sexual dimorphic growth where one sex, in many cases the females, grow more than the other. Mixed sex rearing constitutes a problem for the aquaculture industry because it means producing at suboptimal capacity when compared to monosex culture. In addition, farming conditions results in many cases in masculinization, which further aggravates the problem if the desired sex is the females. Thus, the control of sex ratios is of major importance for many farmed species (Piferrer 2001; Budd et al. 2015). Deciphering the molecular mechanisms involved in gonadal development and the establishment of population sex ratios has then not only basic interest but also is of practical importance for modern fish farming.

Transcriptomic studies on gonadal tissues have been conducted in a relatively large number of fish species, both cultured and not. For example, in the channel catfish (Ictalurus punctatus), the genes differentially expressed (DEG) were described during testis development (Zeng et al. 2016). In fugu (Takifugu rubripes) and in the spotted knifejaw (Oplegnathus punctatus), a larger number of DEG were found in adult testes when compared to ovaries (Du et al. 2017; Wang et al. 2017). However, the number of studies focusing on sex-related differences precisely during sexual development and with a genomics approach are much more limited, and include those carried out in Nile tilapia (Oreochromis niloticus) (Tao et al. 2013), turbot (Scophthalmus maximus) (Ribas et al. 2016), zebrafish (Danio rerio) (Ribas et al. 2017) and yellow river carp (Cyprinus carpio) (Jia et al. 2018).

The European sea bass (Dicentrarchus labrax) stands as the third most important cultured species of marine fish in Europe with a production of $~ 180$ thousand tons per year (Food and Agriculture Organization of the United Nations 2016). Its production has benefited from advances in reproduction and the implementation of breeding programs (reviewed in Felip and Piferrer, 2018; Wang et al. 2019). In this species, females grow about $30 \%$ more than males (Saillant et al. 2001). However, temperature during early development can affect sex ratios, favoring a higher number of males in the populations (reviewed in Vandeputte and Piferrer, 2018). This problem can be even more aggravated if males undergo precocious maturation as it slows down their growth (Carrillo et al. 2015). Thus, there is interest in producing monosex female stocks. 
107 The European sea bass is one of the richest species in terms of genomic resources

108 among cultured fish, which include the availability of the genome and Single

109 Nucleotide Polymorphism (SNP) markers, among others. The European sea bass has a

110 small genome size (675 Mb) with a total of 26,719 annotated genes (Tine et al. 2014;

111 Chaves-Pozo et al. 2017) and has 24 haploid chromosome pairs (Aref'yev 1989). It is a

112 gonochoristic species with a polygenic sex determination system with both genetic and

113 environmental influences (Piferrer et al. 2005; Vandeputte et al. 2007; Vandeputte and

114 Piferrer 2018). Although the genetic factors are still not known, efforts have been done

115 towards identifying sex-determinant markers to aid in genetic selection programs.

116 Studies using $\sim 6,700$ SNP markers showed that there are at least three loci linked to sex

117 (Palaiokostas et al. 2015) but these may be family-specific. Studies on the effects of

118 food supply during early development evidenced changes in energy balance during

119 testicular development (Díaz et al. 2014). In a similar manner, transcriptomic profiles of

120 differentiating gonads subjected to different temperatures or estrogen treatments

121 identified the involvement of steroidogenic- and epigenetic-related genes (Díaz and

122 Piferrer 2015; Díaz and Piferrer 2017). Recently, the epigenetic regulation of key sex-

123 related genes has been reported and a method based on the analysis of epimutations to

124 predict sex in the European sea bass devised (Anastasiadi et al. 2018). Nevertheless, a

125 study of the transcriptomic changes that occur during sexual development had never

126 been carried out.

127

128 The objective of this study was to fill this gap. To do so, we transcriptomically analyzed

129 sexually undifferentiated, differentiating and differentiated gonads. Gene expression

130 levels were evaluated by using a homologous custom-made microarray enriched with

131 reproduction-related genes. Studying transcriptomes by using a microarray platform

132 provides accuracy and reproducibility of the performed analysis and allows studying a

133 broad range, if not all, of the transcripts of the genome (Shi et al. 2006). In particular,

134 our custom microarray contained $78.5 \%$ of the annotated coding genes of the European

135 sea bass genome, thus providing a powerful molecular tool to study gene expression

136 patterns of this species. 


\section{Materials and Methods}

\section{European sea bass gonad sampling}

139 In order to obtain the widest possible range of expressed transcripts, gonads were

140 dissected from fish $(1.5 \pm 0.5 \mathrm{~cm}$ of standard length, SD) at 110 days post fertilization

141 (dpf), when they are still morphologically undifferentiated but can be sexed by

142 analyzing the expression of sex-markers (i.e., cyp19ala (Blázquez et al. 2008), when

143 differentiating at $250 \mathrm{dpf}(12.7 \pm 5.7 \mathrm{~cm}$ of SD and $11.2 \pm 0.6 \mathrm{~cm}$ of SD in females and

144 males, respectively) and when differentiated at $350 \mathrm{dpf}(16 \pm 1.3 \mathrm{~cm}$ and $14.8 \pm 1.1 \mathrm{~cm}$,

145 in females and males, respectively). The set of samples consisted of eleven gonads at

$146110 \mathrm{dpf}$, twelve gonads (six testes and six ovaries) at $250 \mathrm{dpf}$ and eighteen gonads (nine

147 testes and nine ovaries) at $350 \mathrm{dpf}$. When possible, gonads were fully isolated from fish

148 at 250 and $350 \mathrm{dpf}$ and thus gonadal tissue was devoid of any other tissue. However, a

149 clean gonad isolation was not feasible in younger fish (110 dpf) due to their extremely

150 small size, and thus some epithelial contamination could not be ruled out.

152 Microarray platform

153 The microarray platform used in the present study consists of 1,417 Agilent control

154 probes and a total of 43,803 transcript probes that represent 20,978 genes of which

15520,028 have two probe copies each while the rest have between 1 to 6 copies per gene

156 (Supplementary Table S1). Genes with known reproduction-related functions had at

157 least four copies. Microarray was based on sequences obtained from two 454 FLX

158 Titanium runs on European sea bass gonad tissues at different ages (from $40 \mathrm{dpf}$ up to 6

159 years), a former custom European sea bass microarray platform (GPL13443) available

160 in our laboratory (Díaz et al. 2014; Díaz and Piferrer 2015), a previously published

161 European sea bass microarray (Ferraresso et al. 2010) and a battery of selected

162 reproduction canonical genes. Only non-redundant and annotated sequences were

163 selected. This microarray was submitted to Gene Expression Omnibus (GEO) database

164 (Edgar et al. 2002) with the platform number GPL16767 and its functionality was

165 reported in a previous work using European sea bass larvae (Schaeck et al. 2017). In the

166 present work, this microarray has been re-annotated by using the European sea bass

167 genome (Tine et al. 2014) and used to study the gonadal development in the European

168 sea bass. Microarray data of the present study were submitted to GEO and are

169 accessible through GEO Series accession number GSE115841. For a complete list of

170 gene names and abbreviations, see Dataset 1. 


\section{RNA isolation and microarray hybridization}

174 Total RNAs was extracted from 41 gonad samples using RNeasy Mini Kit (Qiagen,

175 Germany) following the manufacturer's instructions. Quantity was determined by a

176 Nanodrop spectrophotometer (Nanodrop Technologies, USA) and quality (RNA

177 integrity number, RIN) measured with a Bioanalyzer (Agilent Technologies, USA).

178 Only RNA samples with a mean RIN $\geq 8.4$ were further processed for microarray

179 analysis. RNA was labelled using the Low Input Quick Amp Labelling Kit, One-Color

180 (Cy3; Agilent Technologies) and cRNA was hybridized overnight with the

181 corresponding buffers during $17 \mathrm{~h}$ at $65^{\circ} \mathrm{C}$ and washed on the following day. Samples

182 were hybridized individually in the European sea bass custom 4x44K Agilent

183 microarray described above at the Parc d'Investigació Biomédica de Barcelona (PRBB)

184 and slides were scanned using an Agilent G2565B microarray scanner (Agilent

185 Technologies, USA). Agilent software was used to avoid saturation and the extraction

186 feature generated the raw data for further pre-processing.

188 Data analysis

189 Statistical analyses were performed with R software (2.13.1 version; www.R-

190 project.org). Array normalization was implemented using the Quantile method in the

191 Linear Models for Microarray Analysis (Limma) R package (Wettenhall and Smyth

192 2004; Ritchie et al. 2015). Potential batch effects were removed by ComBat correction,

193 a bioinformatic tool based on Empirical Bayes algorithms (Chen et al. 2011). Data

194 visualization, Principal Component Analysis of the variance and identification of

195 clusters and outliers (two samples at $350 \mathrm{dpf}$ were detected as outliers and excluded

196 from further analysis) were performed using R. TIGR Multiexperiment Viewer version

$1974.9(\mathrm{TMeV})$ software (Saeed et al. 2003) was used to determine the number of

198 differentially expressed genes (DEG) between sexes at a given stage of development or

199 between stages of development within the same sex. Significance was assessed by

200 Significant Analysis of Microarrays (SAM) statistical test with a False Discovery Rate

201 (FDR) and adjusted $P$ values $<0.01$ and $<0.001$ were applied to identify genes with

202 statistically significant differences in expression. The above-mentioned analysis

203 generated lists of DEG at each stage (110, 250 and $350 \mathrm{dpf})$ in the same sex or in 
204 comparison to the other sex, including the $\log _{2}$ transformation of fluorescence intensity 205 measured for each gene.

207 Gene ontology terms and KEGG pathway analysis

208 The over-represented gene ontology (GO) functional categories of the DEG between

209 females and males at each stage were obtained by GO-terms enrichment analysis using

210 GO.db and topGO packages from the Bioconductor Project (Gentleman et al. 2004;

211 Alexa and Rahnenfuhrer 2016; Carlson 2017) in R software (R Core 2017). The graphs

212 and heatmaps were produced using gplots and ggplot2 packages (Wickham 2009;

213 Warnes et al. 2016).

214

215 We used the Gene Set Variation Analysis (GSVA) from Pathway Processor 2.0 to study

216 the signalling pathways involved in gonadal development. GSVA transforms the gene

217 expression values into a normalized expression matrix with enrichment scores of

218 differentially regulated pathways (DRP) with the corrected $P$ value between males and

219 females at each developmental stage (Beltrame et al. 2013).

220

221 Four pathways involved in sex differentiation: fanconi anemia and wnt signaling

222 pathways, associated with female differentiation (Rodríguez-Marí and Postlethwait

223 2011; Sreenivasan et al. 2014), p53 signaling and cytokine-cytokine interaction receptor

224 pathways, associated with male differentiation (Yasuda et al. 2012; Ribas et al. 2017)

225 were also studied. The lists of genes making-up these pathways were obtained from the

226 Kyoto Encyclopedia of Genes and Genomes (KEGG), using zebrafish as background.

227 The numbers of DEG from these pathways as well as expression values (in $\log _{2}$ Fold

228 Change, FC) were plotted together; upregulated in male $v s$. upregulated in female over

229 time.

230

231 Transcription factors analysis

232 The transcription factors (TFs) present in the microarray were identified with the aid of

233 the TF checkpoint database, a list of TFs compiled from nine databases (Chawla et al.

234 2013). Using this list as background, the percentage of TFs present in the DEG between

235 sexes and differentially expressed at each age was calculated.

236

237 Validation of the microarray 
238 Microarray results were validated by quantitative real time polymerase chain reaction

239 (qPCR) analyzing the expression of twelve genes selected with a wide range of FC

240 values and equal amount of upregulated and downregulated genes when ovaries and

241 testes were compared. Two house-keeping genes were chosen as reference: Elongation

242 factor-1 alpha $(e f-1 \alpha)$ and 40 S ribosomal protein ( $f a u)$ that were previously validated in

243 the European sea bass (Mitter et al. 2009). One hundred nanograms of total RNA were

244 reverse transcribed into cDNA using Superscript III (Invitrogen) and $100 \mathrm{ng}$ of random

245 hexamer primers (Sigma) following the manufacturer's instructions. The reaction was

246 carried out with SYBR Green chemistry (Power SYBR Green PCR Master Mix;

247 Applied Biosystems). qPCR reactions contained 1X SYBR green master mix (Applied

248 Biosystems), $10 \mathrm{pmol}$ of each primer and $1 \mu 1$ of the RT reaction. Samples were run

249 individually and in triplicate in optically clear 384-well plates in Applied Biosystems

2507900 machine. Cycling parameters were: $50^{\circ} \mathrm{C}$ for $2 \mathrm{~min}, 95^{\circ} \mathrm{C}$ for $10 \mathrm{~min}$, followed by

25140 cycles of $95^{\circ} \mathrm{C}$ for $15 \mathrm{~s}$ and $60^{\circ} \mathrm{C}$ for $1 \mathrm{~min}$. Finally, a temperature-determining

252 dissociation step was performed at $95^{\circ} \mathrm{C}$ for $15 \mathrm{~s}, 60^{\circ} \mathrm{C}$ for $15 \mathrm{~s}$ and $95^{\circ} \mathrm{C}$ for $15 \mathrm{~s}$ at the

253 end of the amplification phase. qPCR data were collected by SDS 2.3 and RQ Manager

2541.2 software and relative quantity (RQ) values for each reaction replicate were

255 calculated by the $2 \Delta \Delta C T$ method (Schmittgen and Livak 2008). Primer sequences used

256 for gene expression study are shown in Supplementary Table S2.

\section{Results}

259 Microarray platform and validation

260 Hybridization repeatability and consistency of results was verified in 55 genes related to 261 reproduction and previously selected in turbot (Ribas et al. 2016) and zebrafish (Ribas

262 et al. 2017) to study sex differentiation and reproduction (Supplementary Table S3).

263 Probe copy tendency for 52 of these genes were the same for all the copies and only

264 three of them (representing $\sim 5 \%$ of the 52 tested probes) showed different probe

265 tendency in at least one of the copies. Some examples of upregulated (Supplementary

266 Fig. S1 a, c, e, g), downregulated (Supplementary Fig. S1 b, d, f, h) or variable (i) gene

267 expression are shown. Since most probes had two or four copies (Supplementary Fig.

$268 \mathrm{jj}$ ) to further evaluate the hybridization accuracy, we determined the magnitude of

269 variation between technical replicates. The mean of the standard deviations for all 54

270 probes ranged between 0.205 and 0.347 (Supplementary Fig. 1j). Thus, given the low 
271 standard error among probe copies of the same gene, the average FC value of all probe 272 copies was used for each gene.

273

274 Microarray validation by qPCR for 12 DEGs showed a good correlation between the 275 results obtained either by microarray and $\mathrm{qPCR}$ techniques $\left(\mathrm{R}^{2}=0.748, P=0.0003\right.$;

276 Supplementary Fig. S2a). Additionally, gene expression values of aromatase

277 (cyp19a1a) from samples at different stages of gonadal development (110, 250 and 350

278 dpf) determined either by using microarray and by qPCR, further validated our results

279 (Supplementary Fig. S2b).

280

281

Gonadal transcriptomes overview

282 Samples clustered in two distinctive groups according to sex and within each group 283 samples tended to group according to age, except for males at $350 \mathrm{dpf}$, which showed 284 more variation in the PCA (Fig. 1a). The component 1 of the PCA alone explained $28587.14 \%$ of the variance, while components 2 and 3 contributed to $8.35 \%$ and $1.98 \%$ of the total variance, respectively. Thus, the first three components together explained $97.47 \%$ of variance.

288

289 A total of seven comparisons were analyzed with the SAM statistical test with an 290 adjusted $P$ value $\leq 0.01$ : three between sexes, two within males and two within females 291 at the three different ages (Fig. 1b). Among the 20,978 genes included in the 292 microarray, 64.93\% were differentially expressed at one or several of these 293 comparisons. The number of DEGs between ovaries and testes was 708; 7,639 and 294 6,926, at 110, 250 and 350 dpf, respectively (Fig. 1b, Dataset 1). A larger number of 295 genes were upregulated in females when compared to M: 685 vs. 23 at $110 \mathrm{dpf} ; 3,870$ 296 vs. 3,769 at $250 \mathrm{dpf}$, and 6,097 vs. 829 at $350 \mathrm{dpf}$. Between 110-250 and 250-350 dpf, 297 the number of upregulated genes was 3,564 and 1,100 in females while 451 and 309 in 298 males, respectively. The number of downregulated genes between 110-250 and 250-350 299 dpf was 3,060 and 671 in females while 1,737 and 1,179 in males, respectively. Among 300 the upregulated genes in the developing ovaries, higher FC values were found in 110 $301 \mathrm{dpf}$ and $350 \mathrm{dpf}$ while at $250 \mathrm{dpf}$ FC values were higher in testes when compared to 302 ovaries (Supplementary Table S4). The highest FC values were observed at $250 \mathrm{dpf}(P$ $303<0.001$ ) which was 7.5 and $6.7 \log _{2}$ in males and females, respectively (Dataset 1 ), 
304 indicating important sex-related differences in expression levels (Supplementary Table 305 S4).

307 Gene ontology and gene pathway enrichments along gonadal development

308 The GO term enrichment analysis of the DEGs between $\mathrm{F}$ and $\mathrm{M}$ revealed several 309 categories related to biological processes (BP), molecular function (MF) and cellular 310 component (CC) throughout development (Dataset 2). A total of $39 \mathrm{GO}$ terms in the 311 three categories were enriched during ovarian formation. The $15 \mathrm{GO}$ terms significantly 312 enriched in BP common at 110, 250 and $350 \mathrm{dpf}(P<0.01)$ are shown in Fig. 2a. The 313 three developmental stages were enriched in GO terms related to metabolic processes 314 (GO:0008152, GO:0071704, GO:0044237), catalytic activity (GO:0003824), 315 oxidoreductase activity (GO:0016491), coenzyme and cofactor binding (GO:0050662; 316 GO:0048037), and biosynthetic processes (GO:0009058, GO:1901576). Among the GO 317 terms enriched for testis formation, there were a total of 52 significantly enriched terms 318 that were common at 250 and $350 \mathrm{dpf}$, but none at $110 \mathrm{dpf}$ which were related to 319 catabolic processes (GO:0000956, GO:0006402, GO:0006401), regulation of ion transmembrane activity (GO:1904427, GO:0032414, GO:0034767), regulation of calcium ion (GO:0010524, GO:0050850, GO:0051281, GO:0060316, GO:1901021, 322 GO:1904427) and positive regulation of growth (GO:0045927). Fig. 2b shows the 323 enriched GO terms found for testis formation in BP category $(P<0.02)$.

325 Then, we determined the significantly Differentially Regulated Cellular Pathways 326 (DRP) between males and females along gonadal development. A total of 41, 151 and 106 DRP were found between males and females at 110, 250 and 350, respectively

328 (Dataset 3, $P<0.05$ ). Some of these DRP were related to sex differentiation, for 329 example, at early gonadal development (110 dpf): p53 signaling pathway, steroid 330 hormone biosynthesis or erb $\beta$ signaling pathway; at $250 \mathrm{dpf}$ : wnt signaling pathway, 331 oocyte meiosis or steroid biosynthesis and at $350 \mathrm{dpf}$ : MAPK signaling pathway or 332 cytokine-cytokine receptor interaction among others. A total of 16 DPR were 333 consistently differentially regulated at the three developmental stages in both sexes 334 (Table 1). The lysine degradation, bladder cancer and the nucleotide-binding 335 oligomerization (NOD)-like receptor signaling pathways were upregulated in females at 336 the three gonadal developmental stages when compared to males. The dorso-ventral axis 337 formation pathway was significantly downregulated in females at $110 \mathrm{dpf}$ but 
338 upregulated at 250 and $350 \mathrm{dpf}$. The p53 signaling pathway and the Chagas disease

339 (American trypanosomiasis) pathways showed significance, being upregulated at 110 340 and $350 \mathrm{dpf}$ in females but downregulated at $250 \mathrm{dpf}$ when compared to males. There

341 were two pathways, phosphatidylinositol signaling system and the Erb $\beta$ signaling 342 pathway that were upregulated in females at $110 \mathrm{dpf}$ but at 250 and $350 \mathrm{dpf}$ in males.

343 Finally, there were up to eight pathways upregulated in males when compared to

344 females throughout the studied period: butirosin and neomycin biosynthesis, basal 345 transcription factors, amino sugar and nucleotide sugar metabolism, type II diabetes 346 mellitus, glycine, serine and threonine metabolism, steroid biosynthesis and ribosome 347 and folate biosynthesis pathways.

Expression of canonical genes and pathways related to sex differentiation

350 Of the 54 canonical genes known to be relevant for reproduction and sex differentiation 351 in fish according to the primary literature, 49 of them had sex-related significant 352 differences in at least one of the three ages studied. The majority (80.5\%) were DEG at $250 \mathrm{dpf}$ (Supplementary Table S3). Of the 49 just mentioned above, 25 were pro-female and 24 pro-male genes. Hierarchical clustering analysis and the corresponding heatmaps of the 25 pro-female genes (Fig. 3a) and the 24 pro-male genes (Fig. 3b) showed that gene expression results mostly matched according to their phenotypic gender. The expression profiles of twelve key genes is shown in Fig. 4. Six of them are related to the

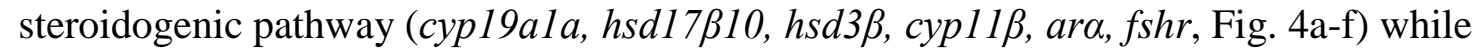
the other six genes are TFs related to sex differentiation (foxl2, sox3, figl $\alpha$, nr5ala, sox $9 b$ and $d m r t 1$, Fig. $4 \mathrm{~g}-1)$. The genes cyp $11 \beta 1$, ar $\alpha, h s d 3 \beta$ and $f s h r$ were upregulated in males when compared to females at $250 \mathrm{dpf}$ and onwards while $h s d 17 \beta 10$ was

362 upregulated in females already at $110 \mathrm{dpf}$. In all these genes, sex-specific significant 363 differences in expression were observed at least in one of the three sampling ages. All genes except $h s d 3 \beta$ had maximal sex-related expression differences at $250 \mathrm{dpf}$. Regarding the six canonical TFs, they were upregulated as expected according to sex: foxl2, sox3 and figla in females while nr5ala, sox $9 b$ and dmrtl in males. All of them were differentially expressed between sexes at least in $250 \mathrm{dpf}$ and some also at $350 \mathrm{dpf}$ (sox3, figla, sfla and sox $9 b$ ).

370 Next, we looked specifically at the four signaling pathways known to be associated with sex differentiation from previous studies (see Materials and methods). Among genes 
372 that constitute these signaling pathways, we looked at the number of DEG and the

373 magnitude of the gene expression values. The two selected pathways related to ovarian

374 development, fanconi anemia (Fig. 5a, b) and wnt (Fig. 5c, d) signaling pathways, had a

375 larger number of DEG and a higher gene expression (FC) values in females. Similarly,

376 when looking among pathways related to testis development, p53 signaling pathway

377 (Fig. 5e, f) and cytokine-cytokine interaction receptor pathway (Fig. 5g, h), they had a

378 larger number of DEG and a higher gene expression (FC) values in males.

The role of transcription factors during gonadal development

381 Our microarray included 2,822 TFs in total, i.e., $13.5 \%$ of all the probes. The proportion 382 of differentially expressed TFs was variable between sexes and across time (Fig. 6). At $383110 \mathrm{dpf} 8.0 \%$ of the DEG were upregulated TFs in ovaries when compared to testes, 384 while no TFs were upregulated in testes. At $250 \mathrm{dpf}$, the percentage of differentially 385 upregulated TFs increased up to $13.0 \%$ in ovaries and $9.6 \%$ in testis. Up to $25.6 \%$ of the 386 DEG at $350 \mathrm{dpf}$ were identified as TFs; $14.5 \%$ upregulated in ovaries and $11.1 \%$ were 387 upregulated in testis.

\section{Discussion}

390

\section{Robustness of the microarray}

392 This study provides a comprehensive transcriptomic analysis of gonad differentiation in 393 the European sea bass using a custom species-specific microarray (Schaeck et al. 2017) 394 that has been here further validated. First, the microarray was completely re-annotated 395 and includes almost $80 \%$ of the genes identified in the European sea bass genome.

396 Quality control showed that it had high reproducibility and accuracy. Transcript 397 expression values were very robust as the standard deviations of probe replicates was 398 very low (average 0.276 for 20,029 the duplicated probes), confirming the high 399 reproducibility of RNA analysis using the Agilent oligo-array (Shi et al. 2006). To date, 400 microarray analyses have been very useful in the study of fish transcriptomes, e.g., 401 (Millan et al. 2010; Jantzen et al. 2011; Tingaud-Sequeira et al. 2013; Schaeck et al. 402 2017). Although in the last years RNA sequencing have gained favor over array 403 platforms, analysis of the same samples with the two different techniques gives similar 404 results (Zhao et al. 2014). Here we provide a validated, fast and cost-effective tool for 
405

406

407

408

409

410

411

412

413

414

415

416

417

418

419

420

421

422

423

424

425

426

427

428

429

430

431

432

433

434

435

436 Three pathways (i.e. lysine degradation, bladder cancer and NOD-like receptor

437

438

aquaculture research to study the expression patterns of genes, including all major reproduction-related genes, in the European sea bass (Schaeck et al. 2017).

\section{Transcriptomic differences between females and males during gonadal development}

PCA classified individuals in well-defined and separated clusters according to sex and stage. At 110 dpf, when gonads were still not histologically differentiated, transcriptomic analysis was already capable of classifying samples according to phenotypic sex. Statistical analysis showed that the highest number of DEG were found in differentiated females when compared to differentiated males, in particular at 250 dpf, probably explained by the fact that sex differentiation in the European sea bass starts earlier in females (Piferrer et al. 2005) as in many other fish species (Piferrer 2001; Devlin and Nagahama 2002). This contrasts with results found in other fish species such as zebrafish (Small et al. 2009), tilapia (Tao et al. 2013) or turbot (Ribas et al. 2016), where male-related genes were enriched with respect to female-related genes. Testis development implied downregulation of genes in a certain stage when compared to the previous developmental stages. This tendency was also observed in turbot (Ribas et al. 2016), supporting the importance of active gene repression for testis development. This is in accordance with the current view stating that positive and negative regulatory loops are required for sex differentiation in vertebrates (Munger et al. 2013; Capel 2017).

There were 15 enriched GO terms in upregulated genes during ovarian development (from $110 \mathrm{dpf}$ to $350 \mathrm{dpf}$ ), all of them related to metabolic functions. In this regard, the metabolic process category was the most enriched one found in the differentiating ovary of the protogynous ricefield eel (Monopterus albus) (Cai et al. 2017) and was described as well for ovarian development in turbot (Ribas et al. 2016). In contrast, we did not find any common GO term in the three developmental stages studied in testis. Nevertheless, 30 common GO terms were found enriched between 250 and $350 \mathrm{dpf}$ in developing males and were related to catabolic processes, regulation and positive regulation of growth, among others.

signaling) showed a consistent upregulation in the ovaries in all stages when compared to testes. Lysine is an essential amino acid required for protein synthesis, enzyme 
catalysis and L-carnitine biosynthesis and thus essential for energy metabolism in all

440 body tissues, including ovaries (Ramseyer and Garling 1994; Hallen et al. 2013). The

441 bladder cancer pathway includes genes involved in gonadal development such as the

442 tumor protein tp53 (Mitra et al. 2006), a gene present in germ cells and that induces

443 apoptosis and atresia in oocytes (Rodriguez-Mari et al. 2010; Sayed et al. 2018). The

444 NOD-like receptor signaling pathways is activated in response to host defense and

445 inflammatory disease response (Caruso et al. 2014) and it is upregulated in human

446 polycystic ovaries (Wang et al. 2014). On the other hand, during testicular development

447 eight pathways were identified, including pathways related to metabolism (e.g.,

448 butirosin and neomycin biosynthesis, amino sugar and nucleotide sugar metabolism), to

449 genetic information processing (e.g., basal transcription factors, type II diabetes mellitus

450 ribosome) and to steroid biosynthesis. A sex-biased representation of these molecular

451 pathways might also be species-specific. Thus, for example, in Japanese flounder

452 (Paralichthys olivaceus) the upregulation of metabolic-related pathways was found in

453 ovaries rather than in testes (Fan et al. 2014). Also, in the tilapia, steroidogenic

454 pathways were more expressed in females than in males, particularly at early stages of

455 development (Tao et al. 2013).

456

Sex-biased expression of canonical genes during sex differentiation

458 We selected 54 pro-female or pro-male genes to study their expression along gonadal

459 development. We found 49 DEGs whose expression matched the expected sex bias

460 described in previous studies of other fish species (see Materials and methods).

461 However, six of the genes upregulated in male European sea bass had been previously

462 described as upregulated in female zebrafish (Ribas et al. 2017), namely: $h s d 3 \beta$,

463 cyp19b1, tradd, erl, fshr and er2b.

464

465 In females, the steroidogenic gene $h s d 17 \beta 10$ was upregulated at $110 \mathrm{dpf}$. The

466 expression of $h s d 17 \beta$, cyp 19ala and star was downregulated in European sea bass at

$467170 \mathrm{dpf}$ in fish previously exposed to high temperature, due to the masculinization of

468 the ovary (Díaz and Piferrer 2017). The cyp19ala gene, a key enzyme responsible for

469 converting androgens into estrogens (Guiguen et al. 2009) is considered an early marker

470 of ovarian differentiation in several fish species, including sea bass (Blázquez et al.

471 2008) and also Atlantic halibut (Hippoglossus hippoglossus) (Matsuoka et al. 2006) and

472 turbot (Ribas et al. 2016), among others. In the present study, cyp19ala showed 
473 differentially expression at $110 \mathrm{dpf}$ but was not significant until $250 \mathrm{dpf}$. Hsd17 $\beta 10$ is a 474 mitochondrial enzyme involved in multiple cellular functions, which include fatty acid 475 oxidation, amino acid degradation and steroid metabolism (Yang et al. 2007; Zschocke 476 2012). In humans, $h s d 17 \beta 10$ is related to neurodegenerative diseases such as Parkinson 477 or Alzheimer and has been fully documented (Zschocke 2012; Yang et al. 2014). In 478 fish, there is a lack of information about this isoform as it has been only described in 479 amphioxus (Branchiostoma belcheri) (Zhang et al. 2008) and zebrafish (He and Yang 480 2009) but no biological functions have been yet ascribed. However, information does 481 exist for other genes of the same family such as $h s d 17 \beta 1$ and $h s d 17 \beta 3$, which are involved in sex steroid biosynthesis: $h s d 17 \beta 1$ is responsible to convert inactive estrone to active estradiol and leads to female sex differentiation while $h s d 17 \beta 3$ is required for 11-ketotestosterone synthesis (Tokarz et al. 2015). Hsd17 $\beta 1$ has been identified in some fish species such as Nile tilapia (Zhou et al. 2005), Atlantic cod (Gadus morhua) (Breton and Berlinsky 2014) and olive flounder (Fan et al. 2014) while hsd17 33 in zebrafish and in medaka (Oryzias latipes) only (Mindnich et al. 2004; Kim et al. 2014). $H s d 17 \beta 1$ was already detected at early stages of development in pre-differentiated fathead minnow (Pimephales promelas) embryos, although its expression was not correlated to any sex in particular (Wood et al. 2015). Recently, $h s d 17 \beta 1$ has been suggested as the sex determining gene in the California yellowtail (Seriola dorsalis), which seems to have a ZW sex determination system (Purcell et al. 2018). In our data, we did not find any differential expression in $h s d 17 \beta 1$ and $h s d 17 \beta 3$ genes but we did it in $h s d 17 \beta 10$. To our knowledge, this is the first time that the $h s d 17 \beta 10$ steroidogenic gene is described in European sea bass and it is detected early in the ovaries. Therefore, it is a candidate to be considered as a novel early ovarian marker in this species, although research on its functional role during ovarian differentiation needs further attention.

500 In males, the first signs of sex-biased expression of canonical reproduction-related genes were detected at $250 \mathrm{dpf}$ onwards and not earlier, indicating that their expression starts somewhere between 110 to $250 \mathrm{dpf}$ as previously showed in fish subjected to high

503 temperature treatments at $170 \mathrm{dpf}$ (Díaz and Piferrer 2015). In the present study, genes 504 involved in the steroidogenic pathway such as $h s d 3 \beta$ or cyp $11 \beta 1$, in androgen action 505 such as $\operatorname{ar} \alpha$, or in gonadotropin signaling, $f s h r$ and $l h r$, were differentially expressed 
506 during testis development, as previously reported (Blázquez and Piferrer 2005; Mazón

507 et al. 2014). In contrast, the gonadotropin subunits $f s h b$ and $l h b$, detected in the gonads

508 of the sea bass in this study, as also described in other fish species (Wong and Zohar

509 2004; von Schalburg et al. 2005; Levavi-Sivan et al. 2010) were not differentially

510 expressed.

511

512 When looking for DEG $(P<0.01)$ in testes compared to ovaries at $110 \mathrm{dpf}$, a total of 15

513 genes were found, although none could be considered as canonical reproduction-related

514 genes. Among them, we identified three genes that were previously described to be

515 expressed in the reproductive system: platelet-derived growth factor beta polypeptide

$516(p d g f b)$, sorting nexin $1(\operatorname{snxl})$ and nuclear transcription factor Y beta $(n f y)$, although

517 there are few data on the role of these genes in testis, not only in fish, but also in

518 mammals. For example, $p d g f b$ is involved in the regulation of many biological

519 processes including embryonic development and sexual phenotype, since alteration of

520 this gene generated male and female infertility in several species, including humans

521 (Donnem et al. 2010). Snx is involved in cellular endocytosis functions and its role in

522 oogenesis was described in the gibel carp (Carassius gibelio) (Wen et al. 2003) while

$523 n f y$ is a pleiotropic transcription factor that participates in multiple processes such as

524 cell proliferation and development ( $\mathrm{Li}$ et al. 2018). For example, it has been detected in

525 breast cancer cells (Lagadec et al. 2014) and it is involved in spermatogenesis (Vanwert

526 et al. 2008) but its specific role in transcriptional regulation is not fully understood

527 although several functional studies have been published so far. It is known that it can

528 bind to the piwill promoter in the germ cells (Chang et al. 2015), but also binds together

529 with the orphan nuclear receptor steroidogenic factor-1 ( $\mathrm{Nr} 5 \mathrm{a} 1)$, to the promoter of $f s h b$

530 gene (Jacobs et al. 2003).

531

532 Next, we looked for canonical KEGG pathways involved in sex differentiation and

533 previously described in some but few fish species. This was the case of two pathways

534 required for ovarian development: the fanconi anemia pathway, identified in zebrafish

535 (Rodríguez-Marí and Postlethwait 2011) and in common carp (Cyprinus carpio) (Jia et

536 al. 2018), and the wnt signaling pathway, identified in zebrafish (Sreenivasan et al.

537 2014) and in rainbow trout (Oncorhynchus mykiss) (Nicol and Guiguen 2011). In the

538 European sea bass, we found that the number of genes differentially expressed ascribed

539 to these two pathways increased at $250 \mathrm{dpf}$ and onwards in the developing ovaries. In 
540 testes, we studied the apoptotic pathway p53 previously described in zebrafish

541 (Rodríguez-Marí et al. 2010), medaka (Yasuda et al. 2012) and spotted knifejaw testes

542 (Oplegnathus punctatus) (Du et al. 2017), and the cytokine-cytokine interaction

543 pathway identified in Japanese flounder (Zhang et al. 2015) and in zebrafish (Ribas et

544 al. 2017) gonads. In the European sea bass, we found an increase in the number of genes

545 differentially expressed and associated with these pathways at $250 \mathrm{dpf}$ that then

546 decreased. Thus, these results confirm that, as occurs in other fish species, these four

547 pathways are also involved in gonad development in the European sea bass.

548

549 Transcription factors during gonadal development

550 TFs tightly control gene expression in a large number of processes including gonadal

551 development (Migeon and Wisniewski 2000) and so, in the last years, many studies

552 have revealed their importance in fish sex differentiation (Herpin and Schartl 2011;

553 Nakamura et al. 2011; Shen and Wang 2014; Tanaka 2016). Consequently, with the aim

554 of deciphering the involvement of TFs in gonadal development in the European sea

555 bass, we studied the expression of TFs already known to be sexually dimorphic. These

556 included foxl2 (Yamaguchi et al. 2007) and figl $\alpha$ (Kanamori et al. 2008), related to

557 ovarian development, and sox9b (Bagheri-Fam et al. 2010), nr5ala (Crespo et al. 2013)

558 and dmrtl (Deloffre et al. 2009) related to testis development, the expression of some

559 being in accordance to what was previously described in the European sea bass gonads

560 fish at $170 \mathrm{dpf}$ and subjected to high temperatures (Díaz and Piferrer 2015). Sox3 was

561 considered as a male-determining gene in ricefish (Oryzias dancena) (Takehana et al.

562 2014) although its expression was related to both oocyte and testis development in other

563 fish species. This is the case found in grouper (Epinephelus coioides) (Yao et al. 2007)

564 and in Japanese flounder (Jeng et al. 2018) with an expression bias towards female

565 development. In the present study, sox3 clearly showed a female bias in the European

566 sea bass gonads.

567

568 Then, we explored the presence of TFs at each specific stage of gonadal development.

569 The number of DE TFs increased as the gonadal development progressed. Thus, at 350

570 dpf, when gonads were fully differentiated, the largest number of DE TFs were

571 detected. In all stages, there was a larger number of DE TFs in females than in males

572 that is in concordance with the largest number of DEGs found in females in this fish

573 species. This skewed number towards females was evident already at $110 \mathrm{dpf}$. DE TFs 
574 were only detected in ovaries, probably due to sex differentiation starting earlier in

575 females (Piferrer et al. 2005) and to the increased activity of the tissue by ovary

576 formation and meiotic division actions (D'Cotta et al. 2001).

577

\section{Conclusions}

579 A species-specific microarray enriched for reproduction-related genes was used to study

580 gene expression during European sea bass gonadal development. In contrast to what had

581 been described in other species, a larger number of DEG and DE TFs were observed in

582 ovaries when compared to testis. The expression profiles of 54 genes previously

583 associated to sex differentiation in other species were examined and the steroidogenic

584 gene $h s d 17 \beta 10$ is described as a promising ovarian marker capable of identifying

585 females as early as $110 \mathrm{dpf}$. Also, three genes: $p d g f b$, snxl and $n f y$, were identified as

586 potential markers for male development. Further, three and eight pathways that are

587 consistently enriched along gonadal development in ovary or testis, respectively, were

588 also identified. Taken together, these results contribute to our understanding of gene

589 expression during sexual development in an economically important species in

590 particular and in non-mammalian vertebrates in general, and emphasize the great

591 diversity, also at the molecular level, of fish sexual development.

592

593 Acknowledgments

594 We would like to thank Dr. Richard Reinhardt for his work on the 454 sequencing of

595 the European sea bass gonads performed at Max Planck Institute for Molecular

596 Genetics, Berlin (Germany). Work was supported by Spanish Government Consolider-

597 Ingenio 2010 grant “Aquagenomics” (ref. CDS2007-0002) to SMK, FM, SZ and FP.

598 BC was supported by an Aquagenomics contract; LR was supported by Aquagenomics

599 postdoctoral contract; ND was supported by Aquagenomics predoctoral contract. NSB

600 was supported by AGL2016-78710-R.

601

\section{Conflict of Interest}

603 The authors declare that they have no competing interests. 
606

607

608

609

610

611

612

613

614

615

616

617

618

619

620

621

622

623

624

625

626

627

628

629

630

631

632

633

634

635

636

637

638

639

640

641

642

643

644

645

646

647

648

649

650

651

652

Alexa A and Rahnenfuhrer J (2016) topGO: Enrichment analysis for gene ontology. R package version 2.30.0.

Anastasiadi D, Vandeputte M, Sanchez-Baizan N, Allal F and Piferrer F (2018) Dynamic epimarks in sex-related genes predict gonad phenotype in the European sea bass, a fish with mixed genetic and environmental sex determination. Epigenetics 13(9): 988-1011. DOI: 10.1080/15592294.2018.1529504.

Aref'yev VA (1989) Cytogenetic analysis and nuclear organization of the sea bass Dicentrarchus labrax. J Ichthyol 29: 1-12.

Bagheri-Fam S, Sinclair AH, Koopman P and Harley VR (2010) Conserved regulatory modules in the Sox 9 testis-specific enhancer predict roles for SOX, TCF/LEF, Forkhead, DMRT, and GATA proteins in vertebrate sex determination. Int J Biochem Cell Biol 42(3): 472-477. DOI: 10.1016/j.biocel.2009.07.001.

Beltrame L, Bianco L, Fontana P and Cavalieri D (2013) Pathway Processor 2.0: a web resource for pathway-based analysis of high-throughput data. Bioinformatics 29(14): 1825-1826. DOI: 10.1093/bioinformatics/btt292.

Blázquez M, González A, Papadaki M, Mylonas C and Piferrer F (2008) Sex-related changes in estrogen receptors and aromatase gene expression and enzymatic activity during early development and sex differentiation in the European sea bass (Dicentrarchus labrax). Gen Comp Endocrinol 158(1): 95-101. DOI: S0016-6480(08)00225-6 10.1016/j.ygcen.2008.06.001.

Blázquez M and Piferrer F (2005) Sea bass (Dicentrarchus labrax) androgen receptor: cDNA cloning, tissue-specific expression, and mRNA levels during early development and sex differentiation. Mol Cell Endocrinol 237(1-2): 37-48. DOI: http://dx.doi.org/10.1016/j.mce.2005.04.001.

Breton TS and Berlinsky DL (2014) Characterizing ovarian gene expression during oocyte growth in Atlantic cod (Gadus morhua). Comp Biochem Physiol Part D Genomics Proteomics 9: 1-10. DOI: 10.1016/j.cbd.2013.11.001.

Budd A, Banh Q, Domingos J and Jerry D (2015) Sex control in fish: approaches, challenges and opportunities for aquaculture. J Mar Sci Eng 3(2): 329-355. DOI: 10.3390/jmse3020329.

Cai J, Yang W, Chen D, Zhang Y, He Z, Zhang W and Zhang L (2017) Transcriptomic analysis of the differentiating ovary of the protogynous ricefield eel Monopterus albus. BMC Genom 18(1): 573. DOI: 10.1186/s12864-017-3953-6.

Capel B (2017) Vertebrate sex determination: evolutionary plasticity of a fundamental switch. Nat Rev Genet 18(11): 675-689. DOI: 10.1038/nrg.2017.60.

Carlson M (2017) GO.db: A set of annotation maps describing the entire Gene Ontology. R package version 3.5.0.

Carrillo M, Espigares F, Felip A, Escobar S, Moles G, Rodríguez R, Victoria Alvarado M, Gómez A and Zanuy S (2015) Updating control of puberty in male European sea bass: A holistic approach. Gen Comp Endocrinol 221: 42-53. DOI: 10.1016/j.ygcen.2015.06.019.

Caruso R, Warner N, Inohara N and Nunez G (2014) NOD1 and NOD2: signaling, host defense, and inflammatory disease. Immunity 41(6): 898-908. DOI: 10.1016/j.immuni.2014.12.010.

Chang GB, Chen R, Xu L, Ma T, Wang HZ, Chen J, Zhang Y, Li ZT, Wan F, Guo XM, $\mathrm{Xu}$ Q, Zhao WM and Chen GH (2015) DNA methylation and NF-Y regulate 
Piwill expression during chicken spermatogenesis. Anim Reprod Sci 162: 95103. DOI: 10.1016/j.anireprosci.2015.09.016.

Chaves-Pozo E, Valero Y, Esteve-Codina A, Gomez-Garrido J, Dabad M, Alioto T, Meseguer J, Esteban MA and Cuesta A (2017) Innate cell-mediated cytotoxic activity of European sea bass leucocytes against nodavirus-infected cells: a functional and RNA-seq study. Sci Rep 7(1): 15396. DOI: 10.1038/s41598-01715629-6.

Chawla K, Tripathi S, Thommesen L, Laegreid A and Kuiper M (2013) TFcheckpoint: a curated compendium of specific DNA-binding RNA polymerase II transcription factors. Bioinformatics 29(19): 2519-2520. DOI: 10.1093/bioinformatics/btt432.

Chen C, Grennan K, Badner J, Zhang D, Gershon E, Jin L and Liu C (2011) Removing batch effects in analysis of expression microarray data: an evaluation of six batch adjustment methods. PLoS One 6(2): e17238. DOI: 10.1371/journal.pone.0017238.

Crespo B, Gómez A, Mazón MJ, Carrillo M and Zanuy S (2013) Isolation and characterization of Ff1 and Gsdf family genes in European sea bass and identification of early gonadal markers of precocious puberty in males. Gen Comp Endocrinol 191(0): 155-167. DOI: http://dx.doi.org/10.1016/j.ygcen.2013.06.010.

D'Cotta H, Fostier A, Guiguen Y, Govoroun M and Baroiller JF (2001) Search for genes involved in the temperature-induced gonadal sex differentiation in the tilapia, Oreochromis niloticus. J Exp Zool 290(6): 574-585. DOI: 10.1002/jez.1108.

Deloffre L, Martins R, Mylonas C and Canario A (2009) Alternative transcripts of DMRT1 in the European sea bass: expression during gonadal differentiation. Aquaculture 293(1-2): 89-99. DOI: 10.1016/j.aquaculture.2009.03.048.

Devlin RH and Nagahama Y (2002) Sex determination and sex differentiation in fish: an overview of genetic, physiological, and environmental influences. Aquaculture 208(3-4): 191-364. DOI: Pii S0044-8486(02)00057-1.

Díaz N and Piferrer F (2015) Lasting effects of early exposure to temperature on the gonadal transcriptome at the time of sex differentiation in the European sea bass, a fish with mixed genetic and environmental sex determination. BMC Genom 16. DOI: $10.1186 / \mathrm{s} 12864-015-1862-0$.

Díaz N and Piferrer F (2017) Estrogen exposure overrides the masculinizing effect of elevated temperature by a downregulation of the key genes implicated in sexual differentiation in a fish with mixed genetic and environmental sex determination. BMC Genom 18. DOI: 10.1186/s12864-017-4345-7.

Díaz N, Ribas L and Piferrer F (2014) Effects of changes in food supply at the time of sex differentiation on the gonadal transcriptome of juvenile fish. Implications for natural and farmed populations. Plos One 9(10). DOI: 10.1371/journal.pone.0111304.

Donnem T, Al-Saad S, Al-Shibli K, Busund LT and Bremnes RM (2010) Co-expression of PDGF-B and VEGFR-3 strongly correlates with lymph node metastasis and poor survival in non-small-cell lung cancer. Ann Oncol 21(2): 223-231. DOI: 10.1093/annonc/mdp296.

Du X, Wang B, Liu X, Liu X, He Y, Zhang Q and Wang X (2017) Comparative transcriptome analysis of ovary and testis reveals potential sex-related genes and pathways in spotted knifejaw Oplegnathus punctatus. Gene 637: 203-210. DOI: 10.1016/j.gene.2017.09.055. 
Edgar R, Domrachev M and Lash AE (2002) Gene Expression Omnibus: NCBI gene expression and hybridization array data repository. Nucleic Acids Res 30(1): 207-210. DOI: 10.1093/nar/30.1.207.

Fan ZF, You F, Wang LJ, Weng SD, Wu ZH, Hu JW, Zou YX, Tan XG and Zhang PJ (2014) Gonadal transcriptome analysis of male and female Olive flounder (Paralichthys olivaceus). Biomed Res Int. DOI: 10.1155/2014/291067.

Ferraresso S, Milan M, Pellizzari C, Vitulo N, Reinhardt R, Canario AVM, Patarnello T and Bargelloni L (2010) Development of an oligo DNA microarray for the European sea bass and its application to expression profiling of jaw deformity. BMC Genom 11: 354. DOI: 10.1186/1471-2164-11-354.

Food and Agriculture Organization of the United Nations F (2016) www.fao.org.

Gentleman RC, Carey VJ, Bates DM, Bolstad B, Dettling M, Dudoit S, Ellis B, Gautier L, Ge YC, Gentry J, Hornik K, Hothorn T, Huber W, Iacus S, Irizarry R, Leisch F, Li C, Maechler M, Rossini AJ, Sawitzki G, Smith C, Smyth G, Tierney L, Yang JYH and Zhang JH (2004) Bioconductor: open software development for computational biology and bioinformatics. Genome Biol 5(10). DOI: 10.1186/gb-2004-5-10-r80.

Guiguen Y, Fostier A, Piferrer F and Chang CF (2009) Ovarian aromatase and estrogens: A pivotal role for gonadal sex differentiation and sex change in fish. Gen Comp Endocrinol 165(3): 352-366. DOI: 10.1016/j.ygcen.2009.03.002.

Hallen A, Jamie JF and Cooper AJ (2013) Lysine metabolism in mammalian brain: an update on the importance of recent discoveries. Amino Acids 45(6): 1249-1272. DOI: 10.1007/s00726-013-1590-1.

He X and Yang S (2009) Comments on 'Significance of developmental expression of amphioxus Branchiostoma belcheri and zebrafish Danio rerio Hsd17b10 in biological and medical research'. J Fish Biol 74(8): 1689-1692. DOI: 10.1111/j.1095-8649.2009.02175.x.

Herpin A and Schartl M (2011) Dmrt1 genes at the crossroads: a widespread and central class of sexual development factors in fish. Febs Journal 278(7): 1010-1019. DOI: $10.1111 /$ j.1742-4658.2011.08030.x.

Jacobs SBR, Coss D, McGillivray SM and Mellon PL (2003) Nuclear factor Y and steroidogenic factor 1 physically and functionally interact to contribute to cellspecific expression of the mouse follicle-stimulating hormone-beta gene. Mol Endocrinol 17(8): 1470-1483. DOI: 10.1210/me.2002-0286.

Jantzen SG, Sanderson DS, von Schalburg KR, Yasuike M, Marass F and Koop BF (2011) A 44K microarray dataset of the changing transcriptome in developing Atlantic salmon (Salmo salar L.). BMC Res Notes 4: 88. DOI: 10.1186/17560500-4-88.

Jeng SR, Wu GC, Yueh WS, Kuo SF, Dufour S and Chang CF (2018) Gonadal development and expression of sex-specific genes during sex differentiation in the Japanese eel. Gen Comp Endocrinol 257: 74-85. DOI: 10.1016/j.ygcen.2017.07.031.

Jia Y, Nan P, Zhang W, Wang F, Zhang R, Liang T, Ji X, Du Q and Chang Z (2018) Transcriptome analysis of three critical periods of ovarian development in Yellow River carp (Cyprinus carpio). Theriogenology 105: 15-26. DOI: 10.1016/j.theriogenology.2017.08.027.

Kanamori A, Toyama K, Kitagawa S, Kamehara A, Higuchi T, Kamachi Y, Kinoshita $\mathrm{M}$ and Hori $\mathrm{H}$ (2008) Comparative genomics approach to the expression of fig alpha, one of the earliest marker genes of oocyte differentiation in medaka (Oryzias latipes). Gene 423(2): 180-187. DOI: 10.1016/j.gene.2008.07.007. 
Kim S, Jung D, Kho Y and Choi K (2014) Effects of benzophenone-3 exposure on endocrine disruption and reproduction of Japanese medaka (Oryzias latipes)-A two generation exposure study. Aquat Toxicol 155: 244-252. DOI: 10.1016/j.aquatox.2014.07.004.

Lagadec C, Vlashi E, Frohnen P, Alhiyari Y, Chan M and Pajonk F (2014) The RNABinding Protein Musashi-1 Regulates Proteasome Subunit Expression in Breast Cancerand Glioma-Initiating Cells. Stem Cells 32(1): 135-144. DOI: 10.1002/stem.1537.

Levavi-Sivan B, Bogerd J, Mananos EL, Gomez A and Lareyre JJ (2010) Perspectives on fish gonadotropins and their receptors. Gen Comp Endocrinol 165(3): 412437. DOI: 10.1016/j.ygcen.2009.07.019.

Li GL, Zhao H, Wang LJ, Wang Y, Guo XQ and Xu BH (2018) The animal nuclear factor Y: an enigmatic and important heterotrimeric transcription factor. American Journal of Cancer Research 8(7): 1106-1125.

Matsuoka MP, van Nes S, Andersen O, Benfev TJ and Reith M (2006) Real-time PCR analysis of ovary- and brain-type aromatase gene expression during Atlantic halibut (Hippoglossus hippoglossus) development. Comp Biochem Physiol B Biochem Mol Biol 144(1): 128-135. DOI: 10.1016/j.cbpb.2006.02.008.

Mazón MJ, Gómez A, Yilmaz O, Carrillo M and Zanuy S (2014) Administration of follicle-stimulating hormone in vivo triggers testicular recrudescence of juvenile European sea bass (Dicentrarchus labrax). Biol Reprod 90(1): 10. DOI: 10.1095/biolreprod.113.110569.

Migeon CJ and Wisniewski AB (2000) Human sex differentiation: From transcription factors to gender. Horm Res 53(3): 111-119. DOI: 10.1159/000023558.

Millan A, Gomez-Tato A, Fernandez C, Pardo BG, Alvarez-Dios JA, Calaza M, Bouza C, Vazquez M, Cabaleiro S and Martinez P (2010) Design and performance of a turbot (Scophthalmus maximus) oligo-microarray based on ESTs from immune tissues. Mar Biotechnol (NY) 12(4): 452-465. DOI: 10.1007/s10126-009-92310 .

Mindnich R, Deluca D and Adamski J (2004) Identification and characterization of 17 beta-hydroxysteroid dehydrogenases in the zebrafish, Danio rerio. Mol Cell Endocrinol 215(1-2): 19-30. DOI: 10.1016/j.mce.2003.11.010.

Mitra AP, Datar RH and Cote RJ (2006) Molecular pathways in invasive bladder cancer: New insights into mechanisms, progression, and target identification. J Clin Oncol 24(35): 5552-5564. DOI: 10.1200/jco.2006.08.2073.

Mitter K, Kotoulas G, Magoulas A, Mulero V, Sepulcre P, Figueras A, Novoa B and Sarropoulou E (2009) Evaluation of candidate reference genes for QPCR during ontogenesis and of immune-relevant tissues of European seabass (Dicentrarchus labrax). Comp Biochem Physiol B Biochem Mol Biol 153(4): 340-347. DOI: 10.1016/j.cbpb.2009.04.009.

Munger SC, Natarajan A, Looger LL, Ohler U and Capel B (2013) Fine time course expression analysis identifies cascades of activation and repression and maps a putative regulator of mammalian sex determination. PLoS Genet 9(7): e1003630. DOI: 10.1371/journal.pgen.1003630.

Nakamura S, Kobayashi K, Nishimura T and Tanaka M (2011) Ovarian germline stem cells in the teleost fish, medaka (Oryzias latipes). Int J. Biol Sci 7(4): 403-409. DOI: $10.7150 / \mathrm{ijbs}$.7.403.

Nicol B and Guiguen Y (2011) Expression profiling of wnt signaling genes during gonadal differentiation and gametogenesis in rainbow trout. Sex Dev 5(6): 318329. DOI: $10.1159 / 000334515$. 
Palaiokostas C, Bekaert M, Taggart JB, Gharbi K, McAndrew BJ, Chatain B, Penman DJ and Vandeputte M (2015) A new SNP-based vision of the genetics of sex determination in European sea bass (Dicentrarchus labrax). Genet Sel Evol 47. DOI: $10.1186 / \mathrm{s} 12711-015-0148-y$.

Piferrer F (2001) Endocrine sex control strategies for the feminization of teleost fish. Aquaculture 197(1-4): 229-281.

Piferrer F, Blázquez M, Navarro L and González A (2005) Genetic, endocrine, and environmental components of sex determination and differentiation in the European sea bass (Dicentrarchus labrax L.). Gen Comp Endocrinol 142(1-2): 102-110. DOI: 10.1016/j.ygcen.2005.02.011.

Purcell CM, Seetharam AS, Snodgrass O, Ortega-Garcia S, Hyde JR and Severin AJ (2018) Insights into teleost sex determination from the Seriola dorsalis genome assembly. BMC Genom 19(1): 31. DOI: 10.1186/s12864-017-4403-1.

R Core T (2017) (ed) R: A language and environment for statistical computing." R Foundation for Statistical Computing URL https://www.R-project.org/. Vienna, Austria.

Ramseyer LJ and Garling DL (1994) Amino acid composition of the ovaries, muscle, and whole body of yellow perch. Prog Fish Cult 56(3): 175-179. DOI: 10.1577/1548-8640(1994)056<0175:aacoto>2.3.co;2.

Ribas L, Liew WC, Díaz N, Sreenivasan R, Orbán L and Piferrer F (2017) Heat-induced masculinization in domesticated zebrafish is family-specific and yields a set of different gonadal transcriptomes. PNAS 114(6): E941-E950. DOI: 10.1073/pnas.1609411114.

Ribas L, Robledo D, Gómez-Tato A, Viñas A, Martínez P and Piferrer F (2016) Comprehensive transcriptomic analysis of the process of gonadal sex differentiation in the turbot (Scophthalmus maximus). Mol Cell Endocrinol 422(C): 132-149. DOI: 10.1016/j.mce.2015.11.006.

Ritchie ME, Phipson B, Wu D, Hu Y, Law CW, Shi W and Smyth GK (2015) limma powers differential expression analyses for RNA-sequencing and microarray studies. Nucleic Acids Res 43(7). DOI: 10.1093/nar/gkv007.

Rodriguez-Mari A, Canestro C, BreMiller RA, Nguyen-Johnson A, Asakawa K, Kawakami K and Postlethwait JH (2010) Sex Reversal in Zebrafish fancl Mutants Is Caused by Tp53-Mediated Germ Cell Apoptosis. PLoS Genet 6(7). DOI: 10.1371/journal.pgen.1001034.

Rodríguez-Marí A, Canestro C, BreMiller RA, Nguyen-Johnson A, Asakawa K, Kawakami K and Postlethwait JH (2010) Sex reversal in zebrafish fancl mutants is caused by tp53-mediated germ cell apoptosis. PLoS Genet 6(7): e1001034. DOI: 10.1371/journal.pgen.1001034.

Rodríguez-Marí A and Postlethwait JH (2011) In: HW Detrich, M Westerfield and LI Zon (ed) The role of fanconi anemia/brca genes in zebrafish sex determination Elsevier Academic Press Inc San Diego, CA 92101-4495 USA.

Saeed AI, Sharov V, White J, Li J, Liang W, Bhagabati N, Braisted J, Klapa M, Currier T, Thiagarajan M, Sturn A, Snuffin M, Rezantsev A, Popov D, Ryltsov A, Kostukovich E, Borisovsky I, Liu Z, Vinsavich A, Trush V and Quackenbush J (2003) TM4: A free, open-source system for microarray data management and analysis. Biotechniques 34(2): 374-378.

Saillant E, Fostier A, Menu B, Haffray P and Chatain B (2001) Sexual growth dimorphism in sea bass Dicentrarchus labrax. Aquaculture 202(3-4): 371-387. DOI: $10.1016 / \mathrm{s} 0044-8486(01) 00786-4$. 
Sayed AEH, Ismail RF and Mitani H (2018) Oocyte atresia in WT (HdrR) and P53 (-/-) medaka (Oryzias latipes) exposed to UVA. Journal of Photochemistry and Photobiology B-Biology 183: 57-63. DOI: 10.1016/j.jphotobiol.2018.04.016.

Schaeck M, Reyes-Lopez FE, Vallejos-Vidal E, Van Cleemput J, Duchateau L, Van den Broeck W, Tort L and Decostere A (2017) Cellular and transcriptomic response to treatment with the probiotic candidate Vibrio lentus in gnotobiotic sea bass (Dicentrarchus labrax) larvae. Fish \& Shellfish Immunology 63: 147-156. DOI: 10.1016/j.fsi.2017.01.028.

Schmittgen TD and Livak KJ (2008) Analyzing real-time PCR data by the comparative CT method. Nat Protoc 3(6): 1101-1108. DOI: 10.1038/nprot.2008.73.

Shen Z-G and Wang H-P (2014) Molecular players involved in temperature-dependent sex determination and sex differentiation in Teleost fish. Genet Sel Evol 46. DOI: $10.1186 / 1297-9686-46-26$.

Shi L, Reid LH, Jones WD, Shippy R, Warrington JA, Baker SC, Collins PJ, de Longueville F, Kawasaki ES, Lee KY, Luo Y, Sun YA, Willey JC, Setterquist RA, Fischer GM, Tong W, Dragan YP, Dix DJ, Frueh FW, Goodsaid FM, Herman D, Jensen RV, Johnson CD, Lobenhofer EK, Puri RK, Scherf U, Thierry-Mieg J, Wang C, Wilson M, Wolber PK, Zhang L, Amur S, Bao W, Barbacioru CC, Lucas AB, Bertholet V, Boysen C, Bromley B, Brown D, Brunner A, Canales R, Cao XM, Cebula TA, Chen JJ, Cheng J, Chu T-M, Chudin E, Corson J, Corton JC, Croner LJ, Davies C, Davison TS, Delenstarr G, Deng X, Dorris D, Eklund AC, Fan X-h, Fang H, Fulmer-Smentek S, Fuscoe JC, Gallagher K, Ge W, Guo L, Guo X, Hager J, Haje PK, Han J, Han T, Harbottle HC, Harris SC, Hatchwell E, Hauser CA, Hester S, Hong H, Hurban P, Jackson SA, Ji H, Knight CR, Kuo WP, LeClerc JE, Levy S, Li Q-Z, Liu C, Liu Y, Lombardi MJ, Ma Y, Magnuson SR, Maqsodi B, McDaniel T, Mei N, Myklebost O, Ning B, Novoradovskaya N, Orr MS, Osborn TW, Papallo A, Patterson TA, Perkins RG, Peters EH, Peterson R, Philips KL, Pine PS, Pusztai L, Qian F, Ren H, Rosen M, Rosenzweig BA, Samaha RR, Schena M, Schroth GP, Shchegrova S, Smith DD, Staedtler F, Su Z, Sun H, Szallasi Z, Tezak Z, Thierry-Mieg D, Thompson KL, Tikhonova I, Turpaz Y, Vallanat B, Van C, Walker SJ, Wang SJ, Wang Y, Wolfinger R, Wong A, Wu J, Xiao C, Xie Q, Xu J, Yang W, Zhang L, Zhong S, Zong Y, Slikker W, Jr. and Consortium M (2006) The MicroArray Quality Control (MAQC) project shows inter- and intraplatform reproducibility of gene expression measurements. Nat Biotechnol 24(9): 1151-1161. DOI: 10.1038/nbt1239.

Small CM, Carney GE, Mo Q, Vannucci M and Jones AG (2009) A microarray analysis of sex- and gonad-biased gene expression in the zebrafish: Evidence for masculinization of the transcriptome. BMC Genom 10: 579. DOI: 10.1186/1471-2164-10-579.

Sreenivasan R, Jiang JH, Wang XG, Bartfai R, Kwan HY, Christoffels A and Orban L (2014) Gonad differentiation in zebrafish is regulated by the canonical wnt signaling pathway. Biol Reprod 90(2): 45:41-10. DOI: 10.1095/biolreprod.113.110874.

Takehana Y, Matsuda M, Myosho T, Suster ML, Kawakami K, Shin-I T, Kohara Y, Kuroki Y, Toyoda A, Fujiyama A, Hamaguchi S, Sakaizumi M and Naruse K (2014) Co-option of Sox3 as the male-determining factor on the Y chromosome in the fish Oryzias dancena. Nature Communications 5. DOI: $10.1038 /$ ncomms5157. 
913

914

915

916

917

918

919

920

921

922

923

924

925

926

927

928

929

930

931

932

933

934

935

936

937

938

939

940

941

942

943

944

945

946

947

948

949

Tanaka M (2016) Germline stem cells are critical for sexual fate decision of germ cells. Bioessays 38(12): 1227-1233. DOI: 10.1002/bies.201600045.

Tao WJ, Yuan J, Zhou LY, Sun LN, Sun YL, Yang SJ, Li MH, Zeng S, Huang BF and Wang DH (2013) Characterization of gonadal transcriptomes from nile tilapia (Oreochromis niloticus) reveals differentially expressed genes. PLoS One 8(5). DOI: 10.1371/journal.pone.0063604.

Tine M, Kuhl H, Gagnaire PA, Louro B, Desmarais E, Martins RST, Hecht J, Knaust F, Belkhir K, Klages S, Dieterich R, Stueber K, Piferrer F, Guinand B, Bierne N, Volckaert FAM, Bargelloni L, Power DM, Bonhomme F, Canario AVM and Reinhardt R (2014) European sea bass genome and its variation provide insights into adaptation to euryhalinity and speciation. Nature Communications 5. DOI: 10.1038/ncomms6770.

Tingaud-Sequeira A, Lozano JJ, Zapater C, Otero D, Kube M, Reinhardt R and Cerda J (2013) A rapid transcriptome response is associated with desiccation resistance in aerially-exposed killifish embryos. Plos One 8(5). DOI: 10.1371/journal.pone.0064410.

Tokarz J, Moeller G, de Angelis MH and Adamski J (2015) Steroids in teleost fishes: A functional point of view. Steroids 103: 123-144. DOI: 10.1016/j.steroids.2015.06.011.

Vandeputte M, Dupont-Nivet M, Chavanne H and Chatain B (2007) A polygenic hypothesis for sex determination in the European sea bass Dicentrarchus labrax. Genetics 176(2): 1049-1057. DOI: 10.1534/genetics.107.072140.

Vandeputte M and Piferrer F (2018) In: HP Wang, F Piferrer and SL Chen (ed) Genetic and environmental components of sex determination in the European sea bass Wiley-Blackwell Hoboken, New Jersey.

Vanwert JM, Wolfe SA and Grimes SR (2008) Binding of RFX2 and NF-Y to the testis-specific histone $\mathrm{H} 1 \mathrm{t}$ promoter may be required for transcriptional activation in primary spermatocytes. J Cell Biochem 104(3): 1087-1101. DOI: $10.1002 /$ jcb. 21694.

von Schalburg KR, Rise ML, Brown GD, Davidson WS and Koop BF (2005) A comprehensive survey of the genes involved in maturation and development of the rainbow trout ovary. Biol Reprod 72(3): 687-699. DOI: 10.1095/biolreprod.104.034967.

Wang H-P, Piferrer F, Chen SL and Shen ZG (2019) Sex Control in Aquaculture, Wiley.

Wang XX, Wei JZ, Jiao J, Jiang SY, Yu DH and Li D (2014) Genome-wide DNA methylation and gene expression patterns provide insight into polycystic ovary syndrome development. Oncotarget 5(16): 6603-6610. DOI: 10.18632/oncotarget.2224.

Wang Z, Qiu X, Kong D, Zhou X, Guo Z, Gao C, Ma S, Hao W, Jiang Z, Liu S, Zhang T, Meng X and Wang X (2017) Comparative RNA-Seq analysis of differentially expressed genes in the testis and ovary of Takifugu rubripes. Comp Biochem and Physiol Part D, Genomics \& proteomics 22: 50-57. DOI: 10.1016/j.cbd.2017.02.002.

Warnes GR, Bolker B, Bonebakker L, Gentleman R, W. H, Liaw A, Lumley T, Maechler M, Magnusson A, Moeller S, Schwartz M and Venables B (2016) gplots: various R programming tools for plotting data. R package version 3.0.1. : https://CRAN.R-project.org/package=gplots.

Wen HJ, Xie J and Gui JF (2003) cDNA cloning and characterization of a novel SNX gene differentially expressed in previtellogenic oocytes of gibel carp. Comp 
961

962

963

964

965

966

967

968

969

970

971

972

973

974

975

976

977

978

979

980

981

982

983

984

985

986

987

988

989

990

991

992

993

994

995

996

997

998
Biochem Physiol B Biochem Mol Biol 136(3): 451-461. DOI: 10.1016/s 10964959(03)00250-1.

Wettenhall JM and Smyth GK (2004) limmaGUI: A graphical user interface for linear modeling of microarray data. Bioinformatics 20(18): 3705-3706. DOI: 10.1093/bioinformatics/bth449.

Wickham H (2009) ggplot2: elegant graphics for data analysis. New York, SpringerVerlag.

Wong TT and Zohar Y (2004) Novel expression of gonadotropin subunit genes in oocytes of the gilthead seabream (Sparus aurata). Endocrinology 145(11): 5210-5220. DOI: 10.1210/en.2004-0558.

Wood RK, Seidel JS and Martyniuk CJ (2015) Transcripts involved in steroid biosynthesis and steroid receptor signaling are expressed early in development in the fathead minnow (Pimephales promelas). Comp Biochem Physiol B Biochem Mol Biol 182: 64-72. DOI: 10.1016/j.cbpb.2014.12.003.

Yamaguchi T, Yamaguchi S, Hirai T and Kitano T (2007) Follicle-stimulating hormone signaling and Fox12 are involved in transcriptional regulation of aromatase gene during gonadal sex differentiation in Japanese flounder, Paralichthys olivaceus. Biochem Biophys Res Commun 359(4): 935-940. DOI: 10.1016/j.bbrc.2007.05.208.

Yang S-Y, He X-Y and Miller D (2007) HSD17B10: A gene involved in cognitive function through metabolism of isoleucine and neuroactive steroids. Mol Genet Metab 92(1-2): 36-42. DOI: 10.1016/j.ymgme.2007.06.001.

Yang S-Y, He XY, Isaacs C, Dobkin C, Miller D and Philipp M (2014) Roles of 17 beta-hydroxysteroid dehydrogenase type 10 in neurodegenerative disorders. J Steroid Biochem Mol Biol 143: 460-472. DOI: 10.1016/j.jsbmb.2014.07.001.

Yao B, Zhou L, Wang Y, Xia W and Gui J-F (2007) Differential expression and dynamic changes of SOX3 during gametogenesis and sex reversal in protogynous hermaphroditic fish. J Exp Zool A Ecol Genet Physiol 307A(4): 207-219. DOI: 10.1002/jez.a.361.

Yasuda T, Oda S, Li Z, Kimori Y, Kamei Y, Ishikawa T, Todo T and Mitani H (2012) Gamma-ray irradiation promotes premature meiosis of spontaneously differentiating testis-ova in the testis of p53-deficient medaka (Oryzias latipes). Cell Death Dis 3. DOI: 10.1038/cddis.2012.133.

Zeng QF, Liu SK, Yao J, Zhang Y, Yuan ZH, Jiang C, Chen AL, Fu Q, Su BF, Dunham $\mathrm{R}$ and Liu ZJ (2016) ranscriptome display during testicular differentiation of Channel catfish (Ictalurus punctatus) as revealed by RNA-seq analysis. Biol Reprod 95(1). DOI: 10.1095/biolreprod.116.138818.

Zhang XY, Hou JL, Wang GX, Jiang HB, Wang YF, Sun ZH, Jiang XF, Yu QH and Liu HJ (2015) Gonadal transcriptome analysis in sterile double haploid Japanese flounder. Plos One 10(11). DOI: 10.1371/journal.pone.0143204.

Zhang Y, Wang L, Shao M, Li J, Li B and Zhang H (2008) A comparative study on the developmental expression of hadh2 in amphioxus and zebrafish. J Fish Biol 72(5): 1215-1222. DOI: 10.1111/j.1095-8649.2007.01747.x.

Zhao S, Fung-Leung W-P, Bittner A, Ngo K and Liu X (2014) Comparison of RNA-seq and microarray in transcriptome profiling of activated T cells. Plos One 9(1). DOI: 10.1371/journal.pone.0078644.

Zhou LY, Wang DS, Senthilkumaran B, Yoshikuni M, Shibata Y, Kobayashi T, Sudhakumari CC and Nagahama Y (2005) Cloning, expression and characterization of three types of 17 beta-hydroxysteroid dehydrogenases from 
999

1000

1001

1002

1003

1004

1005

1006

1007

1008

1009

1010

1011

1012

1013

1014

1015

1016

1017

1018

1019

1020

1021

1022

1023

1024

1025

1026

1027

1028

1029

1030

1031

1032

1033 the Nile tilapia, Oreochromis niloticus. J Mol Endocrinol 35(1): 103-116. DOI: 10.1677/jme.1.01801.

Zschocke J (2012) HSD10 disease: clinical consequences of mutations in the HSD17B10 gene. J Inherit Metab Dis 35(1): 81-89. DOI: 10.1007/s10545-0119415-4. 


\section{Figure Legends}

1035

1036 Figure 1. Overview of transcriptomic changes during European sea bass sex

1037 differentiation. a) Principal component analysis of microarray results at three

1038 developmental stages: 110, 250 and 350 days post fertilization (dpf). Samples cluster

1039 together by gender: females (pink ellipse), males (blue ellipse). b) Number of

1040 differentially expressed genes found along gonadal development (110, 250 and $350 \mathrm{dpf})$

1041 for the seven comparisons analyzed using the SAM test.

1042

1043 Figure 2. Common Biological Processes Gene Ontology terms at 110, 250 and 350

1044 days post fertilization (dpf) of differentially expressed genes during European sea bass

1045 sex differentiation a) Female-related genes $(P<0.01)$ b) Male-related genes $(P<0.02)$.

1046

1047 Figure 3. Heatmap of the microarray expression data for 49 out of 5 reproduction-

1048 related canonical genes: a) 25 up- and b) 24 downregulated genes in females. Each row

1049 represents a gene and each column represents a group of fish by age and sex: (M110 = 8

1050 males at 110 days post fertilization $(\mathrm{dpf}), \mathrm{M} 250=6$ males at $250 \mathrm{dpf}$ and M350 $=9$

1051 males at $350 \mathrm{dpf} ; \mathrm{F} 110=4$ females at $110 \mathrm{dpf}$ ); F250 $=6$ females at $250 \mathrm{dpf}$ and F350 $=$

10529 females at $350 \mathrm{dpf}$. The key color represents the level of expression scaled by gene

1053 (yellow: high expression and blue: low expression). The dendrograms inform of the

1054 similarity between genes and between the different samples. Notice that all genes were

1055 grouped as pro-female and pro-male as expected from studies in other species. See

1056 Dataset 1 for a complete list of gene names and abbreviations.

1057

1058 Figure 4. Changes in expression of a set of canonical genes related to sex

1059 differentiation and reproduction in female and male gonads during European sea bass

1060 sex differentiation. a-f) Canonical genes of the steroidogenic pathway. g-l) Canonical

1061 transcription factors. Abbreviations: dpf, days post fertilization; $*=P<0.05 ; * *=P<$

$1062 \quad 0.01 ; * * *=P<0.001)$.

1063

1064 Figure 5. Number of differentially expressed genes (DEG; left panels) and fold change

1065 of reproduction-related pathways (right panels) during European sea bass sex

1066 differentiation (pink, females; blue, males): a-b) Fanconi anemia signaling pathway, c-

1067 d) Wnt signaling pathway, e-f) p53 signaling pathway, g-h) Cytokine-cytokine 
1068 interaction receptor signaling pathway. In the left panels data is expressed as the total 1069 number of genes (absolute values) differentially expressed at each time of development, 1070 in the right panels data is expressed as fold change using male values at $110 \mathrm{dpf}$ as 1071 control group set at 0 .

1072 Figure 6. Diagram showing at three ages during European sea bass sex differentiation 1073 the percentage of pro-male and pro-female transcription factors (TFs) differentially 1074 expressed at each developmental stage of female-related genes, in pink or male-related 1075 genes, in blue.

1076

1077

1078 